\title{
Regulation of Phytosiderophore (PS) and Yellow Stripe-1 (YS1) Transporter Activity by Sulphur (S) and that of High-Affinity Sulphate (SULTR1; 1) Transporter by Iron (Fe) in Wheat
}

\author{
Vasundhara Sharma ${ }^{1}$, Ranjeet Ranjan Kumar ${ }^{2}$, \\ Raghunath Pandey ${ }^{3}$ and Bhupinder Singh ${ }^{4 *}$
}

\author{
${ }^{1}$ Division of Plant Physiology, Indian Agricultural Research Institute, New Delhi, India \\ ${ }^{2}$ Division of Biochemistry, Indian Agricultural Research Institute, New Delhi, India \\ ${ }^{3}$ Division of Soil Science and Agricultural Chemistry, Indian Agricultural Research Institute, \\ New Delhi, India \\ ${ }^{4}$ Nuclear Research Laboratory, CESCRA, Indian Agricultural Research Institute, \\ New Delhi, India \\ *Corresponding author
}

\section{A B S T R A C T}

\section{Keywords}

Iron deficiency, Sulphur,

Phytosiderophore, Uptake transporter, SULTR1; 1, YS1

Article Info

Accepted:

09 December 2017

Available Online:

10 January 2018
Deficiency of micronutrients in soil particularly, that of $\mathrm{Fe}$ is a major nutritional and production constraint worldwide. We hypothesize a role of sulphur nutrition in altering the Fe deficiency tolerance response of crop plants. Present investigation was conducted to elucidate the role of $\mathrm{S}$ in regulating uptake and in-plant partitioning of $\mathrm{Fe}$ in bread and durum wheat through a field and a nutrient solution culture experiment. $\mathrm{S}$ application to wheat, on low Fe field soil $(<4 \mathrm{ppm})$, increased the shoot Fe concentration and grain yield significantly. Results from the hydroponic studies, which supported the field level observations, showed that an increase in Fe uptake by Fe deficient plants under $\mathrm{S}$ sufficiency is mediated via a higher release of PS and that S deficiency inhibits the root synthesis and release of PS. Transcript expression analysis revealed an up regulation of YS1 transporter and a down regulation of SULTR1; 1 transporter at increasing S nutrition. Interestingly, SULTR1; 1 expression was up regulated only in the presence of Fe. The study concludes that $\mathrm{S}$ nutrition is critical for Fe deficiency tolerance response of crops and indicates a reverse regulation of $S$ nutrition by Fe under low $S$.

\section{Introduction}

Wheat, a staple food crop of millions of Indians and of those in other developing countries, is facing huge challenge of poor input use efficiency, grain productivity and quality particularly in the Indo-gangetic wheat belt. Increasing malnutrition among the burgeoning population further compounds the challenge. Increasing the micronutrient concentration of grain cereals such as wheat therefore assumes significance and is currently a high-priority research area (Cakmak, 2008; White and Broadley, 2009; Govindaraj, 2015). Among micronutrients, Fe deficiency is most common in calcareous or alkaline soils and 
prevalent in human population affecting the health of over three billion people worldwide (Lindsay and Schwab, 1982; Aciksoz et al., 2011). Although, Fe is present in sufficient quantities in most soils but its deficiency occurs mainly in terms of its availability for plant uptake. It is, thus, important to elucidate mechanisms that increase $\mathrm{Fe}$ availability for plant uptake from the immobilized/locked Fe fractions of the soil. For making this immobilized $\mathrm{Fe}$ to mobilized form dicotyledonous species possess Strategy I (Reduction strategy) which involves acidification of the soil by specific $\mathrm{H} \neg+-$ ATPases, resulting in an increase of $\mathrm{Fe}$ solubility and reduction of the $\mathrm{Fe}+3$ by specific root reductases (Briat and Lobreaux, 1997; Hell and Stephan, 2003), whereas in monocotyledonous species, Strategy II (Chelation Strategy) is present which involves the biosynthesis and secretion of mugineic acid family of PS (Takahshi et al., 2011; Kobayashi and Nishizawa, 2012). The precursor of PS is sulphur containing amino acid methionine so Fe uptake can be increased by increasing S supplies (Astolfi et al., 2012).

Importance of PS in improving the mobilisation of Fe and zinc ( $\mathrm{Zn}$ ) has been well documented (Cakmak et al., 1998). PS release follows a diurnal pattern with maximum release during early morning (Takagi et al., 1984). Inter and intra species variation for the release of PS and their role in $\mathrm{Fe}$ nutrition under Fe deficiency has been documented in wheat (Khobra et al., 2014). It has been demonstrated that $\mathrm{S}$ re-supply to deficient plants allowed the restoration of their capacity to cope with Fe shortage (Astolfi et al., 2010). In addition, it is shown that the $\mathrm{S}$ supply in form of sulphate can increase synthesis (Kuwajima and Kawai, 1997) and release of PS in Fe-deficient barley roots to improve the capacity of these plants to cope with Fedeficiency (Römheld and Marschner, 1990). The impact of $\mathrm{Fe}$ deprivation on the $\mathrm{S}$ assimilation pathway has been recently investigated in durum wheat (Ciaffi et al., 2013). These metallophores although can bind with metals other than $\mathrm{Fe}$ and $\mathrm{Zn}$, highest affinity is reported for Fe (III) leading to predominance of Fe-PS complex which is taken up by the roots through YS1/YSL family transporters (Curie et al., 2001). YS1 transporters are high affinity transporters which are up-regulated under Fe deficiency condition (Murata et al., 2006). S is taken up by plants as sulphate through the activity of different high affinity sulphate transporters under conditions of low $S$ availability. SULTR1; 1 is an important root specific high affinity sulphate transporter with a $\mathrm{Km}$ of 3.6 $\pm 0.6 \mu \mathrm{M}$ in cereal crops (Takahashi et al., 2000). Effect of S nutrition on PS synthesis and uptake of Fe-PS complex has not yet been conclusively elucidated in wheat. The present study, thus, hypothesizes that $\mathrm{S}$ metabolism in plants impinge upon and is important determinant of the $\mathrm{Fe}$ metabolism and that optimum $\mathrm{S}$ nutrition of crops may increase PS mediate Fe availability for plant uptake and Fe deficiency tolerance of wheat. The aim of present study was to measure the effect of $S$ application on $\mathrm{Fe}, \mathrm{S}$ content and yield attributes, changes in PS production and release as affected by $\mathrm{S}$ availability and the transcript expression of sulphate transporter SULTR1;1 and Fe-PS transporter YS1 in bread and durum wheat under Fe sufficient and deficient condition.

\section{Materials and Methods}

\section{Field experiment}

Field study was conducted in the year 2014-15 at Indian Agricultural Research Institute (IARI) using bread and durum wheat, cv. HD2967 and HI-8713 respectively, procured from the Division of Genetics and Plant Breeding, IARI, New Delhi. Soil at the experimental site was alkaline with a $\mathrm{pH}$ of 8.0-8.5 and <4ppm 
Fe and 11 ppm S. A basal dose of phosphorus (@60 kg $\mathrm{P}_{2} \mathrm{O}_{5} \mathrm{ha}^{-1}$ ) and potassium (@60 kg $\mathrm{K}_{2} \mathrm{O}$ ha $^{-1}$ ) was applied at sowing. Urea was applied as a source of nitrogen (@120 kg N ha-1) in two equal splits while different $S$ levels viz., 0, 30 and $60 \mathrm{~kg} \mathrm{~S}^{-1}$ soil (referred respectively as $\mathrm{S} 0, \mathrm{~S} 30$ and $\mathrm{S} 60$ ) were maintained using gypsum $\left(\mathrm{CaSO}_{4} \cdot 2 \mathrm{H}_{2} \mathrm{O}\right)$.

The experiment was laid out in Randomized Complete Block Design and subplots size was $5 \mathrm{~m} \times 3 \mathrm{~m}$. Observations recorded were yield attributes and $\mathrm{Fe}$ and $\mathrm{S}$ content of shoot. Shoot $\mathrm{Fe}$ and $\mathrm{S}$ content of bread and durum wheat were measured at 40, 70 and 120 DAS while grain yield was recorded at harvest.

\section{Iron and sulphur content}

A known amount of dried tissues were subjected to diacid digestion using HNO3 and HClO4 (9:4) following established protocol. The Fe concentration in acid digests of plant samples were measured by Atomic Absorption Spectroscopy (AAS) at $248.3 \mathrm{~nm}$ whereas tissue $\mathrm{S}$ content was determined following turbidimetric method (Tabatabai and Bremner, 1970). Fe and S content were calculated and expressed as $\mu \mathrm{g}$ Fe plant ${ }^{-1}$ and $\mu \mathrm{g} \mathrm{S}$ plant $^{-1}$, respectively.

\section{Hydroponics experiment}

\section{Nutrient solution culture}

Seeds of bread and durum wheat cultivars were surface sterilized by rinsing for $3 \mathrm{~min}$ in $70 \%$ ethanol followed by $10 \mathrm{~min}$ in $15 \%$ hydrogen peroxide solution and finally in distilled water and were sown on autoclaved sand in plastic trays. Trays were kept in a seed germinator in dark at $25^{\circ} \mathrm{C}$ and were watered as and when necessary. After three days of germination, the trays with emerging seedlings were moved to light to prevent etiolation. Five days old healthy seedlings were gently removed from sand and transferred to the nutrient solution (NS) culture. The roots were washed off the sand particles with deionized water prior to transfer (Zhang et al., 1991) to the $S$ and Fe deficient and sufficient solutions i.e., 0, 1.2 and $2.5 \mathrm{mM} \mathrm{SO}_{4}$ (Zuchi et al., 2012) as $\mathrm{K}_{2} \mathrm{SO}_{4}$ and 1 and $100 \mu \mathrm{M} \mathrm{Fe}$ as Fe ${ }^{\mathrm{III}}$ EDTA (Khobra et al., 2014), in glass tanks (10 liter capacity) with darkened sides to prevent algal growth (Fig. 1) and under continuous aeration. Plants were grown in a climate chamber under $300 \mu \mathrm{mol} \mathrm{m} \mathrm{m}^{-2} \mathrm{~s}^{-1}$ PAR at leaf level and $14 \mathrm{~h} / 10 \mathrm{~h}$ day/night regime (temperature $27^{\circ} \mathrm{C}$ diurnal; $20^{\circ} \mathrm{C}$ nocturnal; relative humidity $80 \%$ ). The $\mathrm{S}$-deficient $\mathrm{NS}$ was prepared by replacing sulphate salts $\left(\mathrm{K}^{+}\right.$, $\left.\mathrm{Mn}^{2+}, \mathrm{Zn}^{2+}, \mathrm{Cu}^{2+}\right)$ with appropriate amounts of chloride salts $\left(\mathrm{K}^{+}, \mathrm{Mn}^{2+}, \mathrm{Zn}^{2+}, \mathrm{Cu}^{2+}\right)$. Concentrations of other nutrients in the solution culture were as follows: $\mathrm{Ca}\left(\mathrm{NO}_{3}\right)_{2}$; $2.00 \mathrm{mM}, \mathrm{KH}_{2} \mathrm{PO}_{4} ; 0.25 \mathrm{mM} \mathrm{MgCl}_{2} ; 1.00$ $\mathrm{mM}, \mathrm{KCl} ; 0.10 \mathrm{mM}, \mathrm{H}_{3} \mathrm{BO}_{3} ; 1.00 \mathrm{mM}$, $\mathrm{MnSO}_{4} ; \quad 0.50 \mathrm{mM}, \quad \mathrm{CuCl}_{2} ; \quad 0.20 \mathrm{mM}$, $\left(\mathrm{NH}_{4}\right)_{2} \mathrm{Mo}_{7} \mathrm{O}_{24} ; 0.02 \mathrm{mM}$ and $\mathrm{ZnCl}_{2} ; 0.001$ $\mathrm{mM}$. All the chemicals used for preparation of nutrient solution were of AR grade. The nutrient solution was changed every three days to maintain the $\mathrm{pH}$ of 5.6 to 5.8 throughout the experimental duration. Total biomass was determined at 21 days of plant growth after transfer to the nutrient solution. For this shoot and root were collected and dried in hot air oven at $70^{\circ} \mathrm{C}$ for 4 hours and then at $60^{\circ} \mathrm{C}$ till constant weight were reached and their dry weight were recorded. Root release of PS, diurnal pattern of PS release and PS content of roots were determined at different days of plant growth in $\mathrm{Fe}$ and $\mathrm{S}$ deficient and sufficient treatments and their combinations, in bread and durum wheat cultivars.

\section{Phytosiderophore content in root tips}

PS content was determined in root tips of bread and durum seedlings at 11DAT. Wheat seedlings were removed from the respective NS treatments at 2 hours after the onset of light and their root tips (about $3 \mathrm{~mm}$ ) were 
collected and homogenized to a fine powder with liquid nitrogen. Distilled water at $100^{\circ} \mathrm{C}$ was added to aliquots of the powdered tissue (500 $\mu \mathrm{l} \mathrm{mg}^{-1} \mathrm{FW}$ ) and homogenates were incubated for $10 \mathrm{~min}$ at $80^{\circ} \mathrm{C}$.Insoluble material was removed by $10 \mathrm{~min}$ centrifugation in a centrifuge at $12,000 \mathrm{rpm}$ and the pellet was then re-extracted with 500 $\mu 1$ of boiling water as described above. After a further centrifugation step, the supernatant was used for determination of PS content in root tips using the Fe-mobilization assay (Reichman and Parker, 2007) - modified from Takagi (1976) and Gries and Runge (1995).

\section{Collection of root exudates and determination of phytosiderophore release}

PS release from wheat plants was analyzed at 8,11 and 14DAT by determining PS content in root washings. A subset of 10 plants was removed from the nutrient solution at $2 \mathrm{~h}$ after the onset of the light period and the roots were washed two times for $1 \mathrm{~min}$ in deionised water. Root systems were submerged into 20 $\mathrm{ml}$ deionised water for $4 \mathrm{~h}$ with continuous aeration. Thereafter, micropur (10 mg 1-1) (Roth, Karlsruhe, Germany) was added to prevent microbial degradation of PS. PS content in root washings were determined using the Fe-mobilization assay (Reichman and Parker, 2007) - modified from Takagi (1976) and Gries and Runge (1995). Mean average PS release over 8, 11 and 14DAT was calculated to ascertain the treatment effect.

\section{Diurnal rhythm of phytosiderophore release}

Diurnal rhythm of PS release from the roots was studied at 11DAT by collecting the PS, following the method described earlier in this section, over the 24 hour cycle at a regular interval of 3 hours i.e. 6AM -9AM, 9AM12PM, 12PM-3PM, 3РM-6PM, 6РM-9PM, 9PM-12AM, 12AM-6AM. The samples were stored at $-20^{\circ} \mathrm{C}$ until the estimation of PS. Measurement of PS was done following the Fe mobilization method (Reichman and Parker, 2007) - modified from Takagi (1976) and Gries and Runge (1995).

\section{Transcript expression of $S$ and Fe uptake transporters}

Transcript expression profile of SULTR1; 1 and YS1gene was studied in the root tissues of 11 day old bread and durum wheat seedlings under $\mathrm{Fe}$ and $\mathrm{S}$ sufficient and deficient treatment combinations as detailed earlier.

Total RNA isolation, complementary DNA (cDNA) synthesis and real time polymerase chain reaction (RT-PCR)

$100 \mathrm{mg}$ of root tissue was ground in liquid nitrogen. $1 \mathrm{ml}$ of trizol was added to it and kept for 5 minutes at room temperature in mortar itself. The contents were then transferred to a $1.5 \mathrm{ml}$ Eppendorf and $200 \mu \mathrm{l}$ chloroform was added with thorough mixing. It was followed by 15 minutes incubation at room temperature and centrifuged at 13,000 rpm for 15 minutes at $4^{\circ} \mathrm{C}$. Aqueous phase was transferred to fresh tubes and $0.5 \mathrm{ml}$ of isopropanol was added, stored at room temperature for $15 \mathrm{~min}$ and again centrifuged at $13,000 \mathrm{rpm}$ for 15 minutes at $4^{\circ} \mathrm{C}$. Supernatant was discarded and the pellet was washed in $500 \mu 1$ of $70 \%$ chilled ethanol and centrifuged at 13,000 rpm for $15 \mathrm{~min}$ at $4^{\circ} \mathrm{C}$. Supernatant was again discarded and the pellet was allowed to dry for 10-15 minutes in incubator at $37^{\circ} \mathrm{C}$ and eluted in $50 \mu \mathrm{l}$ DEPC treated $\mathrm{H} 2 \mathrm{O}$ and incubated at $60^{\circ} \mathrm{C}$ for 10 minutes, and RNA was stored at $80^{\circ} \mathrm{C}$. cDNA synthesis was carried out by using Revert Aid H Minus First Strand cDNA synthesis kit (Thermo scientific, USA) as per the instructions of manufacturer's protocol. Quantitative RT-PCR analysis was carried out by using KAPA SYBR Green qPCR mix on a Bio-Rad CFX96 machine using gene specific 
primers for high affinity sulphate (SULTR1.1, Accession no JX896648) and Fe-PS complex transporter (HvYS1, Accession no AB214183; http://www.ncbi.nlm.nih.gov/) and actin as follows: SULTR1;1-FB (5'AGCCTCTGCAT ACCTCAGGA3') and SULTR1;1-RB (5'ACTGGACCGATGGCTATGTC3') for SULTR1;1; HvYS1-FB (5'GCCTTGTT TAG CGTTCTTGC3') HvYS1-RB (5'GTAAG CCCTGTCCCGTATGA3') for YS1 and ACT-F (5'AGCGAGT CTTCATAG GGCG ATTGT3') and ACT-R (5'TAGCTCTG GGTTCGAGTGGCATTT3') for actin gene.

Reactions were run in Bio-radqRT-PCR CFX 96 machine using the standard cycling program. Relative quantification and qRTPCR efficiency for the target genes were calculated according to Pfaffl (2001).

\section{Statistical analysis}

All analyses were conducted in three $(n=3)$ replications and data are expressed as mean \pm standard deviation (SD) using SPSS 16.0. Significant differences were established by posthoc comparisons (Duncan analysis) at $\mathrm{P}<$ 0.05 .

\section{Results and Discussion}

\section{Field experiment}

\section{Yield attributes}

$\mathrm{S}$ application caused a significant increase in the number of spikes per unit area in bread wheat over durum wheat. A significant increase in grain and biological yield, across wheat varieties was also measured at S30 over S0 (Table 1). However, the variation in grain and biological yield between S30 and S60 was insignificant. Bread wheat, in general, gave more grain and biological yield than the durum wheat. A similar pattern of variation and cultivar and $\mathrm{S}$ effect was observed for harvest index and straw yield.

\section{Shoot $\mathrm{S}$ and Fe content}

The shoot $\mathrm{Fe}$ content on per plant basis showed a significant increase from 40 to 120 DAS for both bread and durum wheat cultivars. Plant Fe also increased significantly with an increase in $\mathrm{S}$ application for both cultivars. However, the $\mathrm{S}$ response on $\mathrm{Fe}$ accumulation was higher for bread than durum wheat. Even without S application (S0) the bread wheat accumulated significantly higher root and shoot Fe than durum wheat (Table 2).

Whereas, shoot $\mathrm{S}$ content on per plant basis measured a significant four to ten folds increase from 40 to 120 DAS for both the experimental wheat cultivars. Here too, $S$ content of shoot in bread wheat did not vary significantly with $\mathrm{S}$ availability in the soil unlike durum wheat which showed a $S$ dose dependent increase in shoot. This probably hints at a great $\mathrm{S}$ uptake by durum than bread wheat (Table 2).

\section{Hydroponics experiment}

\section{Biomass}

Shoot mass, was greatly reduced in the absence of both $\mathrm{S}$ and $\mathrm{Fe}(-\mathrm{S}-\mathrm{Fe})$ when compared with $\mathrm{S}$ and $\mathrm{Fe}$ sufficient $(+\mathrm{S} 2+\mathrm{Fe})$ control, the reduction being 22.3 and $30.8 \%$ respectively for bread and durum wheat. Availability of $\mathrm{S}$, irrespective of the level, improved shoot mass of both bread and durum wheat by 10.8 to $19.3 \%$ and 15.6 to $22.7 \%$ $(+\mathrm{S} 1-\mathrm{Fe}$ to $+\mathrm{S} 2-\mathrm{Fe})$ respectively, when compared with the combined $\mathrm{S}$ and $\mathrm{Fe}$ deficient control.

On the other hand, $\mathrm{S}$ deprivation with the addition of $\mathrm{Fe}(-\mathrm{S}+\mathrm{Fe})$ showed only 8.2 and $15.6 \%$ increase in biomass over nutrient deficient control for bread and durum wheat, respectively. However, when compared with nutrient sufficient control, the reduction in shoot mass under $-\mathrm{S}+\mathrm{Fe}$ condition was 16 
and $19.8 \%$ respectively, for the bread and the durum cultivars.

Higher $(+S \neg 2)$ than lower $S(+S 1)$ availability condition with or without $\mathrm{Fe}$, ensured a better shoot growth and thus, suggested that optimal $S$ availability is critical for making use of available Fe in wheat (Fig. 1a, c).

Changes in root biomass across various $\mathrm{S}$ and $\mathrm{Fe}$ availability condition reveal a higher proliferation of roots in bread wheat than durum wheat under conditions of $\mathrm{S}$ and $\mathrm{Fe}$ deficiency.

Durum plants produced $44.1 \%$ more roots under nutrients sufficient conditions while a reduction in roots mass $(-16.6 \%)$ over respective nutrient deficient controls was measured for the bread wheat (Fig. 1b, d).

These results indicate greater Fe deficiency sensitivity or $\mathrm{Fe}$ requirement of bread wheat than durum wheat which causes a greater proliferation of roots in the former cultivar.

\section{Phytosiderophore content in root tips}

Concentration of the total PS synthesized and available for release (Table 2) under different $\mathrm{Fe}$ and $\mathrm{S}$ availability conditions at11DAT in bread (Fig. 2a) and durum (Fig. 2b) wheat reveals a higher availability of PS in roots of bread wheat under $\mathrm{S}+\mathrm{Fe}$ - condition which matched the respective PS release profile.

On the other hand, under similar $\mathrm{S}$ and $\mathrm{Fe}$ availability condition durum wheat did not release PS despite a substantially higher PS level in the root tips.

\section{Phytosiderophore release}

Mean average root release of PS measured over 8, 11 and 14 DAT (Supplementary table $\mathrm{S} 1$ ) under variable availabilities of $\mathrm{Fe}$ and $\mathrm{S}$ is shown in Figure 2. Bread wheat (Fig. 2c), in general, released a higher amount of PS ( three times) than durum wheat (Fig. 2d) across the $\mathrm{S}$ and $\mathrm{Fe}$ nutrient treatments. Induction of PS occurred mainly under $\mathrm{Fe}$ deficiency with highest measured release of PS observed in + S2-Fe treatment for both bread and durum wheat $(2.22$ and $0.87 \mathrm{nmol}$ $\mathrm{Fe}$ equivalent/g root fw, respectively). However, PS release under dual nutrient deficiency i.e. $-\mathrm{S}-\mathrm{Fe}$ is significantly reduced for both bread and durum wheat.

\section{Diurnal pattern of PS release by roots}

Root release of PS under different $\mathrm{Fe}$ and $\mathrm{S}$ nutrient availability condition clearly indicates that the day and night release pattern of PS is independent of the nutrient availability across the wheat cultivars and follows a similar diurnal rhythm for PS release in both bread and durum wheat with a maximum release between 9 AM-12 PM (Fig. 3).

The differences between treatments were observed only with respect to the magnitude of PS release. Highest release was measured at 2-3 h (8-9AM) after onset of light period and continued till $3 \mathrm{pm}$ followed by a decline at the later hours. Higher diurnal release of PS was observed in bread wheat (Fig. 3a) as compared to durum wheat (Fig. 3b).

\section{Relative expression of sulphate (SULTR1; 1) and iron (YS1) transporter}

Transcript expression pattern of sulphate transporter (Fig. 4a) and Fe-PS complex transporter (Fig. 4b) was investigated in root tissues of bread and durum wheat under varied $\mathrm{S}$ and $\mathrm{Fe}$ availability treatments. 
Table.1 Effect of different level of applied sulphur $\left(\mathrm{S}_{0}, \mathrm{~S}_{30}\right.$, and $\left.\mathrm{S}_{60} \mathrm{~kg} \mathrm{ha}^{-1}\right)$ on grain yield and yield attributes of bread (cv. HD-2967) and durum (cv. HI-8713) wheat under field condition

\begin{tabular}{|c|c|c|c|c|c|}
\hline $\begin{array}{l}\text { Wheat Cultivars } \\
\text { (C) }\end{array}$ & $\begin{array}{c}\text { Sulphur treatment } \\
\left(\mathbf{k g ~ h a}^{-1}\right)\end{array}$ & $\begin{array}{c}\text { Grain yield } \\
\text { (t/ha) }\end{array}$ & Straw yield (t/ha) & $\begin{array}{c}\text { Harvest Index } \\
(\%)\end{array}$ & $\begin{array}{l}\text { Spikelet Number } \\
\left(\text { No. } \mathbf{~ m}^{-2}\right)\end{array}$ \\
\hline \multirow[t]{3}{*}{ HD-2967 } & $\mathrm{S}_{0}$ & $4.0^{\mathrm{B}} \pm 0.1$ & $5.8^{\mathrm{A}} \pm 0.0$ & $40.3^{C} \pm 0.7$ & $301.7^{\mathrm{B}} \pm 4.4$ \\
\hline & $\mathrm{S}_{30}$ & $4.7^{\mathrm{A}} \pm 0.2$ & $6.0^{\mathrm{A}} \pm 0.4$ & $44.1^{\mathrm{B}} \pm 0.5$ & $338.3^{\mathrm{A}} \pm 4.4$ \\
\hline & $S_{60}$ & $5.2^{\mathrm{A}} \pm 0.1$ & $6.4^{\mathrm{A}} \pm 0.1$ & $45.1^{\mathrm{A}} \pm 0.5$ & $351.3^{\mathrm{A}} \pm 1.9$ \\
\hline \multicolumn{2}{|c|}{ Mean } & 4.6 & 6.1 & 43.2 & 330.5 \\
\hline \multirow[t]{3}{*}{ HI-8713 } & $\mathrm{S}_{0}$ & $3.0^{\mathrm{b}} \pm 0.1$ & $5.3^{\mathrm{a}} \pm 0.3$ & $36.1^{c} \pm 0.2$ & $298.3^{c} \pm 4.4$ \\
\hline & $\mathrm{S}_{30}$ & $4.0^{\mathrm{a}} \pm 0.1$ & $6.4^{\mathrm{a}} \pm 0.3$ & $38.7^{\mathrm{b}} \pm 0.3$ & $330.0^{\mathrm{b}} \pm 2.9$ \\
\hline & $\mathrm{S}_{60}$ & $4.2^{\mathrm{a}} \pm 0.2$ & $6.5^{\mathrm{a}} \pm 0.4$ & $39.6^{\mathrm{a}} \pm 0.3$ & $342.3^{\mathrm{a}} \pm 1.5$ \\
\hline \multicolumn{2}{|c|}{ Mean } & 3.7 & 6.1 & 38.1 & 323.6 \\
\hline \multirow[t]{3}{*}{ CD at $5 \%$} & $\mathrm{C}$ & 0.3 & NS & 0.4 & 5.2 \\
\hline & S & 0.3 & 0.6 & 0.5 & 6.3 \\
\hline & $\mathrm{CXS}$ & NS & NS & 0.6 & NS \\
\hline
\end{tabular}

Values are mean \pm standard deviation $(n=4)$. Significant differences between samples are indicated by different letters: different capital letters indicate significant differences among different $\mathrm{S}$ levels in bread wheat (HD-2967) (P $<0.05)(\mathrm{n}=4)$; different small letters indicate significant differences among different $\mathrm{S}$ levels in durum wheat (HI8713).

Table.2 Effect of different level of applied sulphur $\left(\mathrm{S}_{0}, \mathrm{~S}_{30}\right.$, and $\left.\mathrm{S}_{60} \mathrm{~kg} \mathrm{ha}^{-1}\right)$ on shoot iron (Fe) and shoot sulphur (S) content of bread (cv. HD-2967) and durum (cv. HI-8715) wheat at different days after sowing (DAS) under field condition

\begin{tabular}{|c|c|c|c|c|}
\hline \multirow{2}{*}{$\begin{array}{l}\text { Wheat Cultivars } \\
\text { (C) }\end{array}$} & \multirow{2}{*}{$\begin{array}{l}\text { Sulphur treatment } \\
\left(\mathrm{kg} \mathrm{ha}^{-1}\right)\end{array}$} & \multicolumn{3}{|c|}{ Crop Growth Stage } \\
\hline & & 40DAS & 70DAS & 120DAS \\
\hline \multicolumn{5}{|c|}{ Shoot Fe content ( $\mu \mathrm{g}$ Fe plant ${ }^{-1}$ ) } \\
\hline \multirow[t]{3}{*}{ HD-2967 } & $\mathrm{S}_{0}$ & $402.4^{\mathrm{A}} \pm 17.7$ & $454.7^{\mathrm{B}} \pm 23.8$ & $2438.3^{\mathrm{B}} \pm 111.4$ \\
\hline & $\mathrm{S}_{30}$ & $373.4^{\mathrm{A}} \pm 52.8$ & $462.8^{\mathrm{B}} \pm 11.8$ & $2793.2^{\mathrm{B}} \pm 78.9$ \\
\hline & $\mathrm{S}_{60}$ & $454.8^{\mathrm{A}} \pm 9.0$ & $711.4^{\mathrm{A}} \pm 36.1$ & $3713.5^{\mathrm{A}} \pm 50.8$ \\
\hline \multicolumn{2}{|c|}{ Mean } & 410.2 & 542.9 & 2981.6 \\
\hline \multirow[t]{3}{*}{ HI-8713 } & $\mathrm{S}_{0}$ & $230.0^{\mathrm{b}} \pm 5.3$ & $350.9^{b} \pm 26.4$ & $1680.4^{\mathrm{c}} \pm 88.5$ \\
\hline & $\mathrm{S}_{30}$ & $285.7^{\mathrm{b}} \pm 15.9$ & $616.3^{\mathrm{a}} \pm 18.5$ & $2336.0^{\mathrm{b}} \pm 96.2$ \\
\hline & $\mathrm{S}_{60}$ & $340.4^{\mathrm{a}} \pm 13.6$ & $748.7^{\mathrm{a}} \pm 14.3$ & $2863.8^{\mathrm{a}} \pm 94.3$ \\
\hline \multicolumn{2}{|c|}{ Mean } & 282.0 & 572.0 & 2293.4 \\
\hline \multirow{2}{*}{\multicolumn{5}{|c|}{$\begin{array}{r}\text { C: } 63.5, \text { S: } 77.7, \text { D: } 77.7, \text { C X S: 109.9, C X D: 109.9, S X D: 134.6, C X S X D: NS } \\
\left.\text { Shoot S content (ug S plant }{ }^{-1}\right)\end{array}$}} \\
\hline & & & & \\
\hline \multirow[t]{3}{*}{ HD-2967 } & $\mathrm{S}_{0}$ & $57.2^{\mathrm{A}} \pm 4.5$ & $310.8^{\mathrm{A}} \pm 19.9$ & $2745.2^{\mathrm{A}} \pm 87.7$ \\
\hline & $\mathrm{S}_{30}$ & $53.7^{\mathrm{A}} \pm 11.2$ & $248.9^{\mathrm{A}} \pm 9.2$ & $2832.2^{\mathrm{A}} \pm 200.7$ \\
\hline & $\mathrm{S}_{60}$ & $61.3^{\mathrm{A}} \pm 5.5$ & $322.2^{\mathrm{A}} \pm 29.5$ & $3057.5^{\mathrm{A}} \pm 120.3$ \\
\hline \multicolumn{2}{|c|}{ Mean } & 57.4 & 294.0 & 2878.3 \\
\hline \multirow[t]{3}{*}{ HI-8713 } & $\mathrm{S}_{0}$ & $73.2^{\mathrm{b}} \pm 1.1$ & $465.0^{\mathrm{c}} \pm 21.7$ & $2613.5^{\mathrm{b}} \pm 300.2$ \\
\hline & $\mathrm{S}_{30}$ & $82.4^{\mathrm{ab}} \pm 6.74$ & $680.7^{\mathrm{b}} \pm 23.2$ & $3227.4^{\mathrm{b}} \pm 16.6$ \\
\hline & $\mathrm{S}_{60}$ & $93.3^{\mathrm{a}} \pm 4.83$ & $816.0^{\mathrm{a}} \pm 45.2$ & $5280.8^{\mathrm{a}} \pm 120.8$ \\
\hline \multicolumn{2}{|c|}{ Mean } & 82.9 & 653.9 & 3707.2 \\
\hline \multicolumn{2}{|c|}{ CD at $5 \%$} & \multicolumn{3}{|c|}{ C: 132.9, S: 162.9, D: 62.9, C X S: 230.4, C X D: 230.4, S X D: 282.1, C X S X D: 399.0} \\
\hline
\end{tabular}

Values are mean \pm standard deviation $(n=4)$.Significant differences between samples are indicated by different letters: different capital letters indicate significant differences among different $\mathrm{S}$ levels in bread wheat (HD-2967) (P $<0.05)(\mathrm{n}=4)$; different small letters indicate significant differences among different $\mathrm{S}$ levels in durum wheat (HI8713). 
Fig.1 Shoot (A and C) and root (B and D) dry weight of bread (HD-2967) and durum (HI-8713) wheat plants grown for 21 days in NS at $1\left({ }^{-} \mathrm{Fe}\right)$ and $100\left({ }^{+} \mathrm{Fe}\right) \mu \mathrm{M}$ FeIII-EDTA and under three S concentrations in the NS i.e. $0\left({ }^{-} \mathrm{S}\right), 1.2\left({ }^{+} \mathrm{S}_{1}\right)$ and $2.5\left({ }^{+} \mathrm{S}_{2}\right) \mathrm{mM}$, deficient, adequate and high, respectively. Data are means \pm SD of three independent replications. Significant differences between samples are indicated by different letters: different capital letters indicate significant differences among different $\mathrm{S}$ levels in 1-Fe condition $(\mathrm{P}<0.05)(\mathrm{n}=3)$; different small letters indicate significant differences among different $\mathrm{S}$ levels in $100-\mathrm{Fe}$ condition
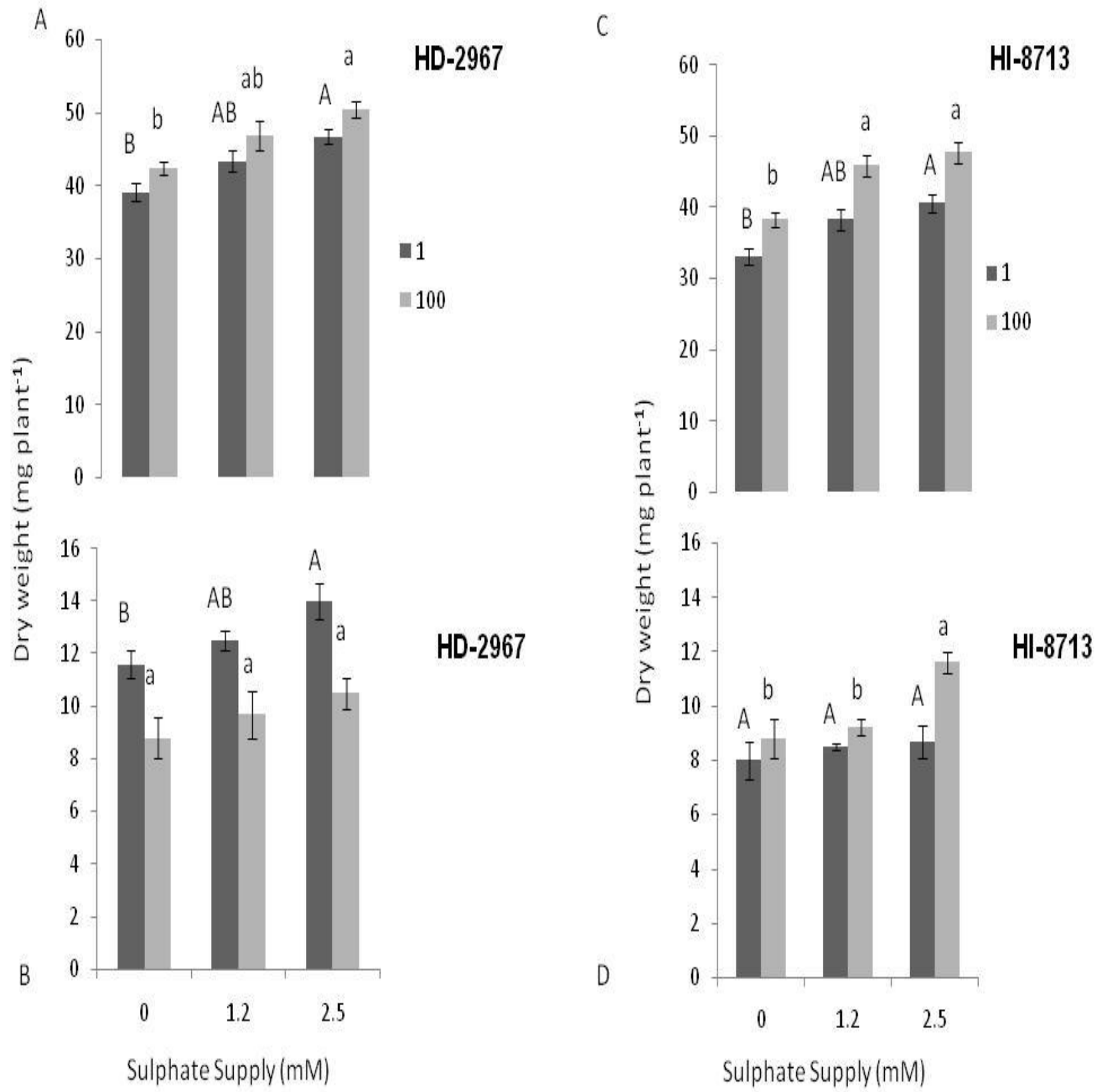
Fig.2 PS content (A and B) and PS release (C and D) of bread (HD-2967) and durum (HI-8713) wheat plants grown on NS at $1\left({ }^{\circ} \mathrm{Fe}\right)$ and $100\left({ }^{+} \mathrm{Fe}\right) \mu \mathrm{M}$ FeIII-EDTA and under three $\mathrm{S}$ concentrations in the NS i.e. $0\left({ }^{-} \mathrm{S}\right), 1.2\left({ }^{+} \mathrm{S}_{1}\right)$ and $2.5\left({ }^{+} \mathrm{S}_{2}\right) \mathrm{mM}$, deficient, adequate and high, respectively. PS content was measured at $11 \mathrm{DAT}$ and is presented as replicate mean $\pm \mathrm{SE}$ while PS release data are means of three independent replications \pm SE at 8,11 and 14 DAT (See supplementary table S1 for individual stage PS release data). Statistics as in Figure 1
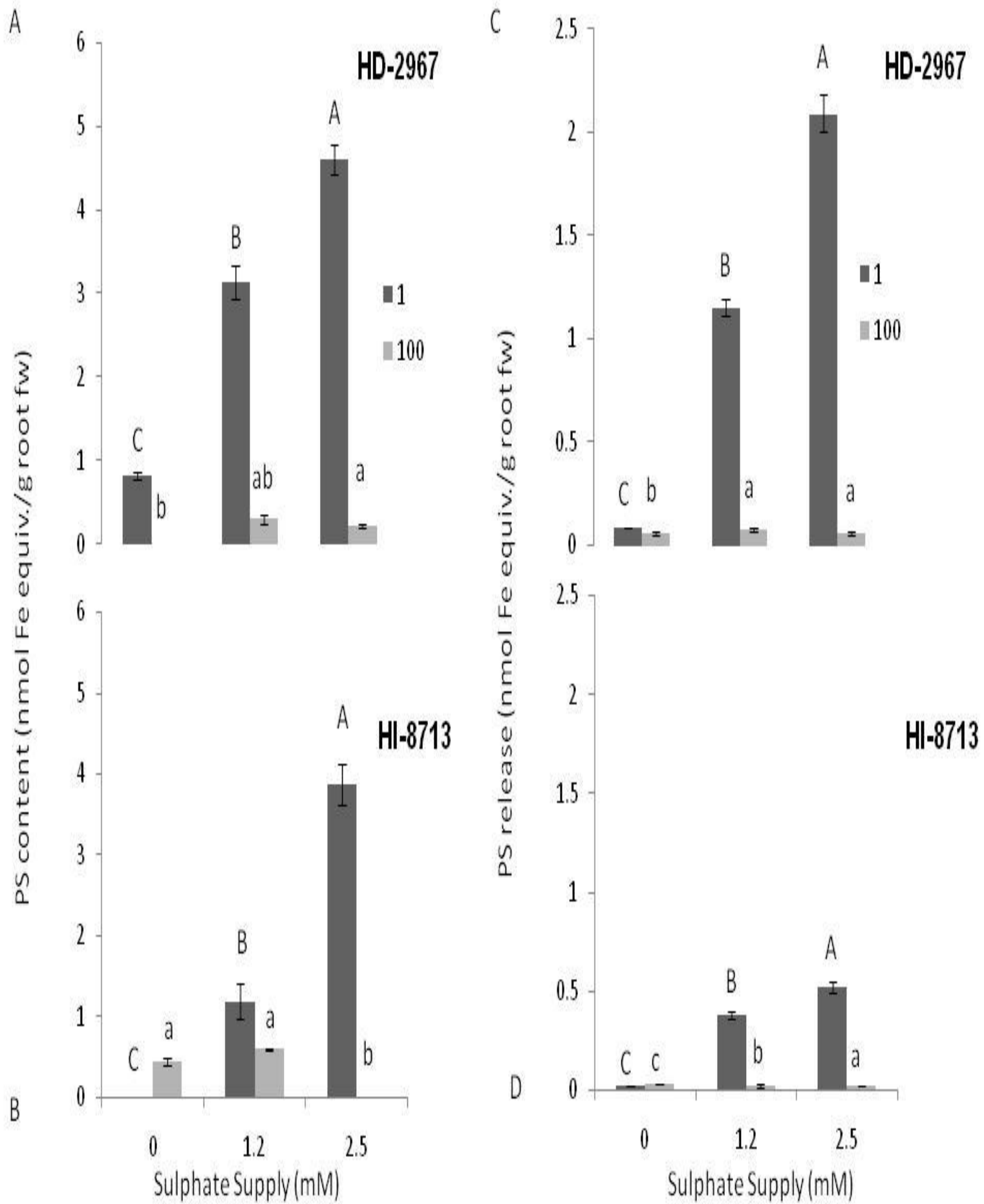
Fig.3 Diurnal release of phytosiderophores (PS) (nmol Fe equiv./g FW) in bread (HD-2967) and durum (HI-8713) wheat plant raised in nutrient solution at $1\left({ }^{(} \mathrm{Fe}\right)$ and $100\left({ }^{+} \mathrm{Fe}\right) \mu \mathrm{M}$ FeIII-

EDTA and under three $\mathrm{S}$ concentrations in the NS i.e. $0\left({ }^{-} \mathrm{S}\right), 1.2\left({ }^{+} \mathrm{S}_{1}\right)$ and $2.5\left({ }^{+} \mathrm{S}_{2}\right) \mathrm{mM}$, deficient, adequate and high respectively at 11 days after transfer (DAT). Data are means \pm SD of three independent replications. Statistics as in Figure 1

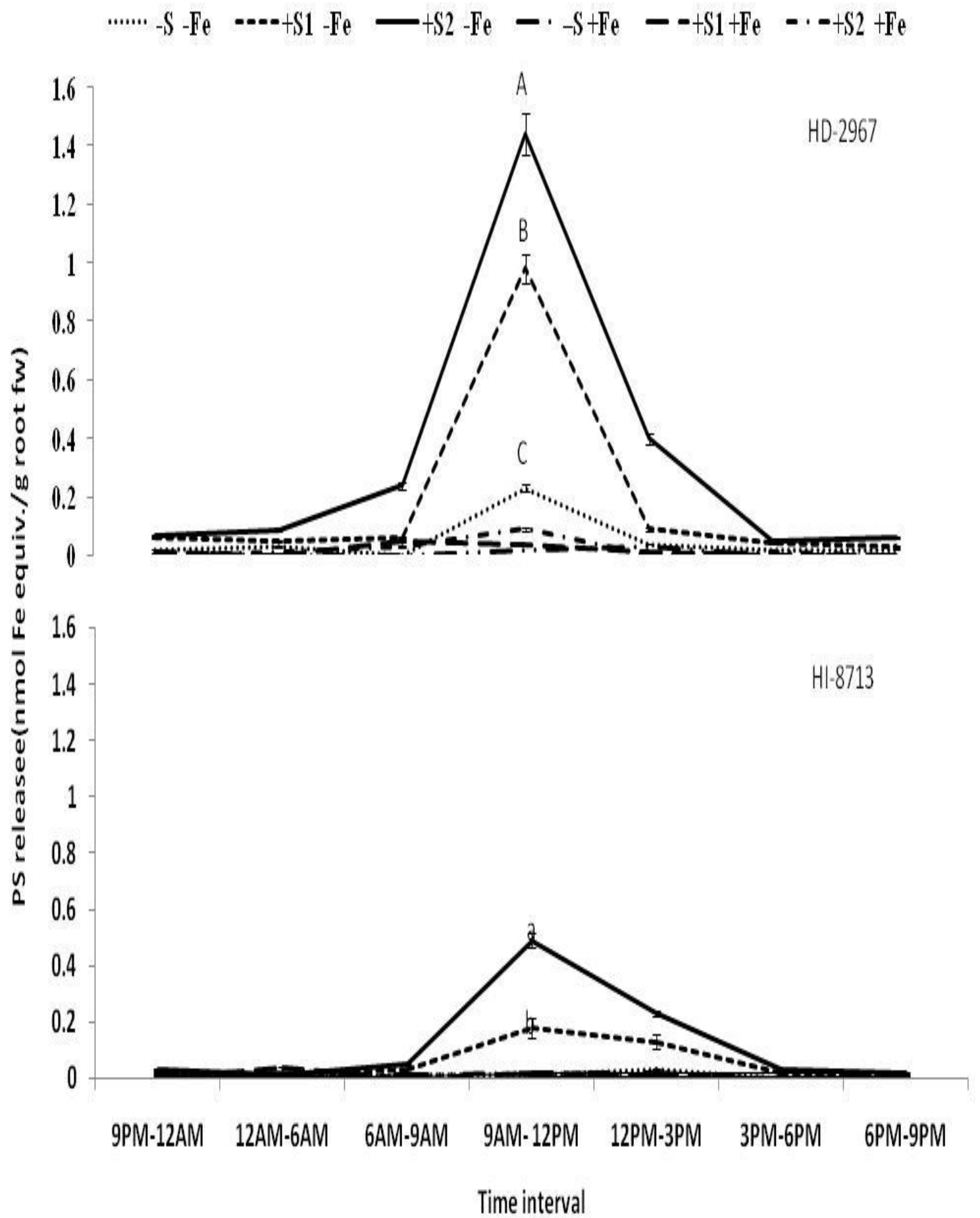


Fig.4 Relative transcript abundance of SULTRI;1 and YS 1 in roots of bread (HD-2967) and durum (HI-8713) wheat grown under different iron and sulphur supply. Data are means \pm SD of three independent replications. Statistics as in Figure 1

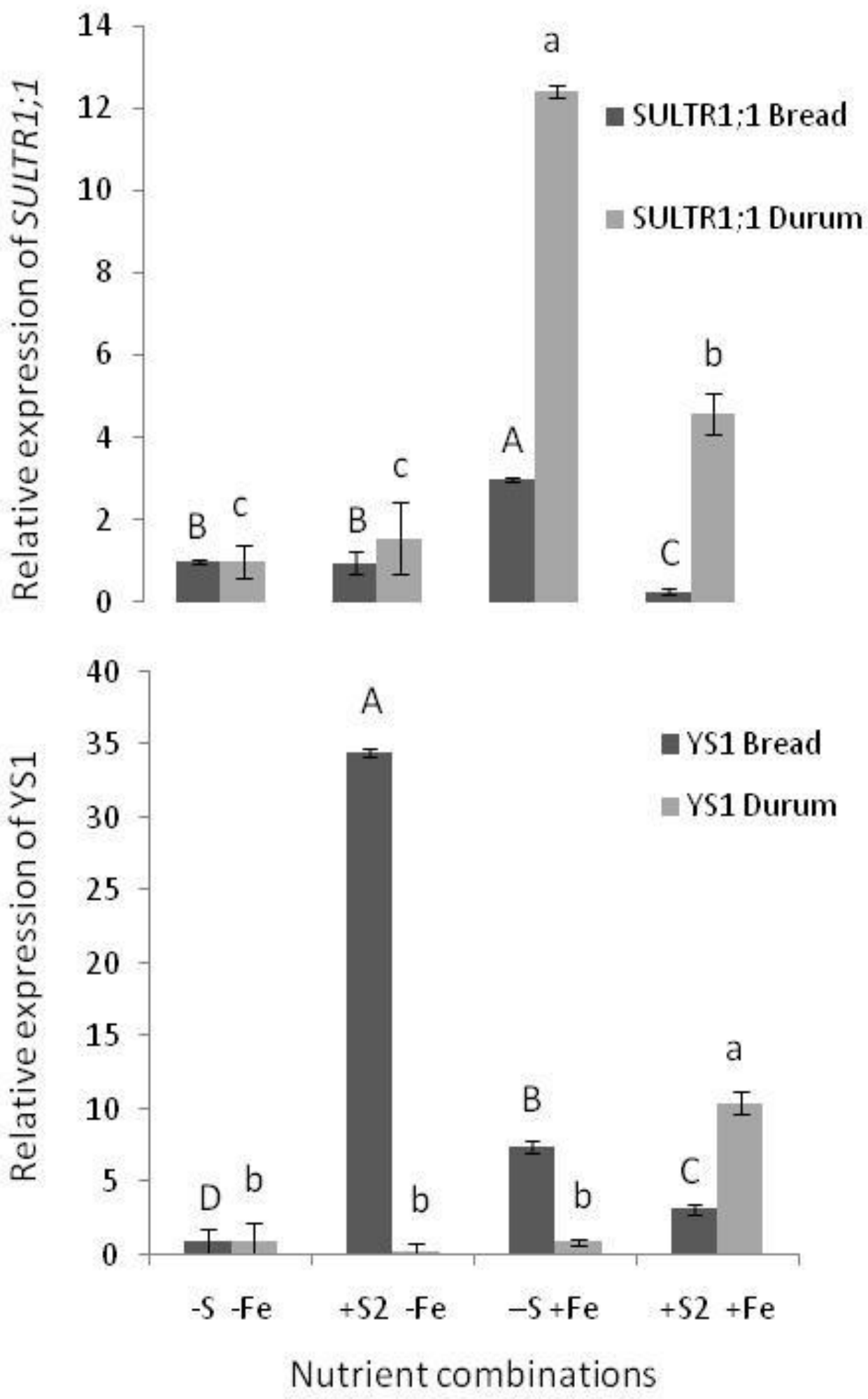


Plate.1 Growth response of bread (HD-2967) and durum (HI-8713) wheat to deficiency and/or sufficiency of iron and sulphur in nutrient solution culture
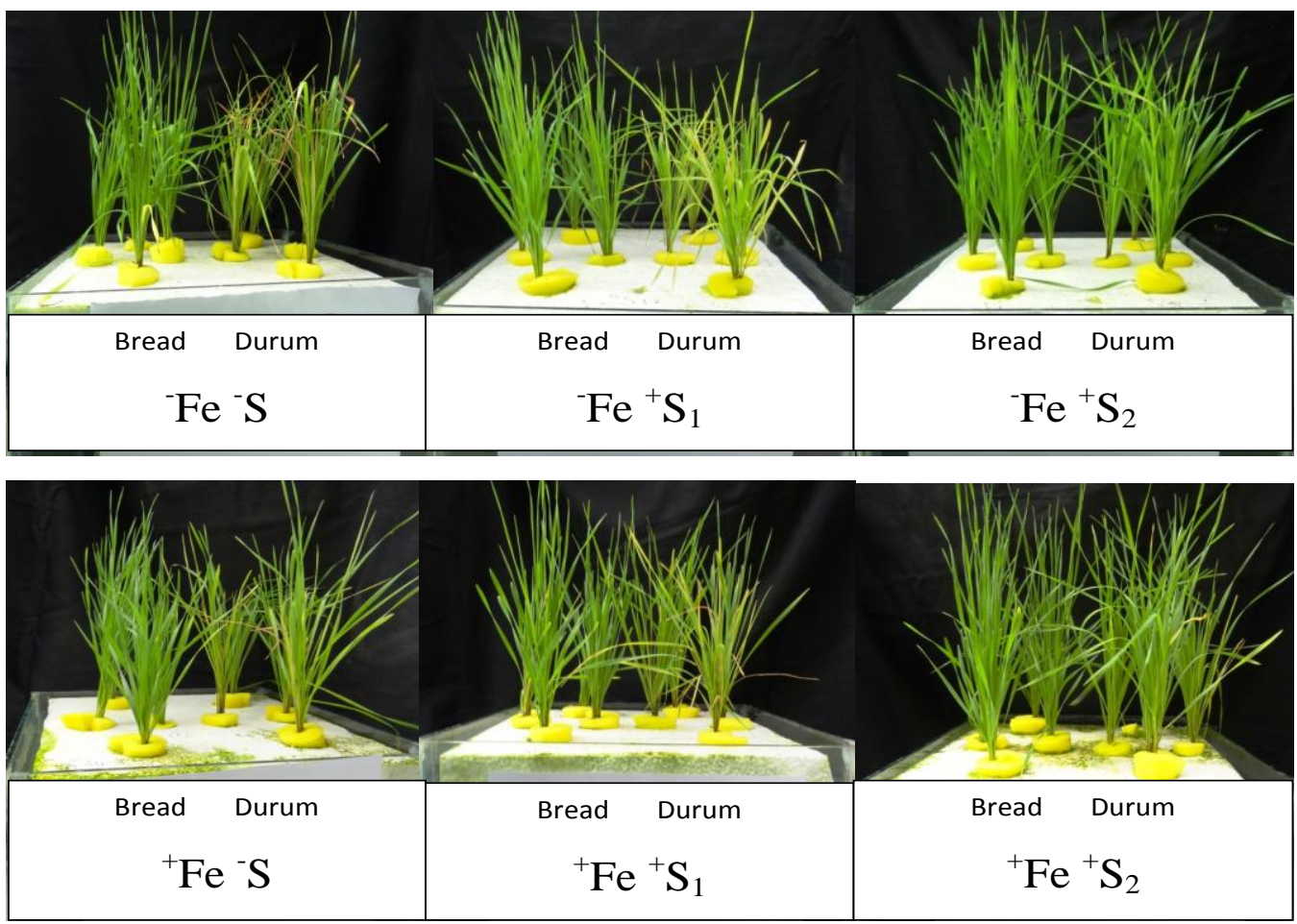

Table S1: Phytosiderophore (PS) release in bread (HD-2967) and durum (HI-8713) wheat varieties raised in nutrient solution at $1 \mu \mathrm{M}\left({ }^{-} \mathrm{Fe}\right)$ and $100 \mu \mathrm{M}\left({ }^{+} \mathrm{Fe}\right) \mathrm{Fe}{ }^{\mathrm{III}}$-EDTA and under three $\mathrm{S}$ concentrations $\left(0\left({ }^{-} \mathrm{S}\right), 1.2\left({ }^{+} \mathrm{S}_{1}\right)\right.$ and $\left.2.5\left({ }^{+} \mathrm{S}_{2}\right) \mathrm{mM}\right)$ at 8,11 and 14 days after transfer (DAT)

\begin{tabular}{|c|c|c|c|c|c|}
\hline \multirow{2}{*}{$\begin{array}{l}\text { Wheat } \\
\text { Cultivars (C) }\end{array}$} & \multirow{2}{*}{$\begin{array}{l}\text { Nutrient } \\
\text { treatment } \\
\text { (T) }\end{array}$} & \multicolumn{3}{|c|}{ Crop Growth Stage (D) } & \multirow[t]{2}{*}{ Mean } \\
\hline & & 8DAT & 11DAT & 14DAT & \\
\hline \multicolumn{6}{|c|}{ Phytosiderophore release (nmol Fe equivalent $\mathrm{g}^{-1}$ root $\mathrm{fw}$ ) } \\
\hline \multirow[t]{6}{*}{ HD-2967 } & -S Fe & 0.08 & 0.17 & 0.02 & 0.09 \\
\hline & ${ }^{+} \mathrm{S}_{1}{ }^{-} \mathrm{Fe}$ & 1.06 & 1.79 & 0.60 & 1.15 \\
\hline & ${ }^{+} \mathrm{S}_{2}{ }_{2}^{-} \mathrm{Fe}$ & 2.85 & 2.22 & 1.19 & 2.09 \\
\hline & $\mathrm{S}^{+} \mathrm{Fe}$ & 0.01 & 0.16 & 0.02 & 0.06 \\
\hline & ${ }^{+} \mathrm{S}_{1}^{+} \mathrm{Fe}$ & 0.01 & 0.11 & 0.11 & 0.08 \\
\hline & ${ }^{+} \mathbf{S}_{2}{ }^{+} \mathbf{F e}$ & 0.02 & 0.09 & 0.06 & 0.06 \\
\hline Mean & & 0.67 & 0.76 & 0.33 & \\
\hline \multirow[t]{6}{*}{ HI-8713 } & $\mathrm{S}^{-} \mathrm{Fe}$ & 0.03 & 0.00 & 0.02 & 0.02 \\
\hline & ${ }^{+} \mathrm{S}_{1}{ }^{-} \mathrm{Fe}$ & 0.38 & 0.65 & 0.17 & 0.40 \\
\hline & ${ }^{+} \mathbf{S}_{2}{ }^{-} \mathbf{F e}$ & 0.59 & 0.87 & 0.20 & 0.52 \\
\hline & ${ }^{-} \mathbf{S}^{+} \mathbf{F e}$ & 0.01 & 0.00 & 0.00 & 0.00 \\
\hline & ${ }^{+} \mathrm{S}_{1}{ }^{+} \mathrm{Fe}$ & 0.01 & 0.03 & 0.03 & 0.02 \\
\hline & ${ }^{+} \mathbf{S}_{2}{ }^{+} \mathrm{Fe}$ & 0.01 & 0.04 & 0.01 & 0.02 \\
\hline Mean & & 0.17 & 0.27 & 0.07 & \\
\hline \multirow[t]{7}{*}{ CD at 5\% } & \multicolumn{2}{|r|}{ (C) } & \multicolumn{2}{|c|}{0.03} & \\
\hline & \multicolumn{2}{|r|}{ (S) } & \multicolumn{2}{|c|}{0.12} & \\
\hline & \multicolumn{2}{|r|}{ (D) } & \multicolumn{2}{|c|}{0.17} & \\
\hline & \multicolumn{2}{|r|}{ (CX S) } & \multicolumn{2}{|c|}{0.27} & \\
\hline & \multicolumn{2}{|r|}{ (CX D) } & \multicolumn{2}{|c|}{0.27} & \\
\hline & \multicolumn{2}{|r|}{$(\mathbf{S ~ X ~ D ) ~}$} & \multicolumn{2}{|c|}{0.34} & \\
\hline & \multicolumn{2}{|r|}{ (C X S X D) } & \multicolumn{2}{|c|}{0.37} & \\
\hline
\end{tabular}


SULTR1; 1 gene was mainly expressed in absence of $\mathrm{S}$ in both bread and durum wheat cultivars and the gene expression was enhanced in the presence of $\mathrm{Fe}$ (under $-\mathrm{S}+\mathrm{Fe}$ ) across the wheat cultivars but about 10 times in durum than bread wheat. Whereas, Fe transporter gene (YS1), expressed more under Fe deficiency condition and $S$ sufficient condition $(+\mathrm{S}-\mathrm{Fe})$ in bread wheat than durum wheat. Some expression was also observed under $\mathrm{S}$ and Fe sufficient condition in durum wheat whereas, in absence of both $\mathrm{S}$ and $\mathrm{Fe}$, a negligible expression was measured.

Sulphur, an essential mineral nutrient, regulates plant metabolism, growth and grain yield production as component of amino acids such as cysteine and methionine besides having role in regulating several other important physiological functions (Muneer et al., 2013). Involvement of sulphur nutrition in nitrogen use efficiency in wheat (Salvagiotti et al., 2009) and Fe uptake in barley (Astolfi et al., 2012) has been reported. However, the interactive effect of $\mathrm{S}$ nutrition on uptake and use of other macro or micro nutrient may depend on their respective availabilities in the soil.

A positive effect of sulphur fertilization on growth attributes (Ciaffi et al., 2013), grain yield (Zhao et al., 1999) and grain quality (Pompa et al., 2009) have been evidenced in different crops (Jarvan et al., 2008). Our result confirmed this as the measure of yield and its attributes indicated a positive impact of sulphur application at S30 over S0 condition. Gilbert et al., (1997) reported a significant effect of sulphur availability on activities of the carboxylating enzymes and synthesis of new proteins. Low soil sulphur impairs the synthesis of Rubisco and cause inhibition/reduced activity of the photosynthetic apparatus leading to a reduced assimilation and storage of carbon (Hawkesford 2000). Sulphur deficiency also causes damage to mitochondrial oxidative phosphorylation system in Arabidopsis thaliana (Ostaszewska-Bugajska and Juszczuk, 2016). Thus increasing sulphur supply increases the protein and enzyme level of plant which in turn increases photosynthesis, respiratory metabolism as well as grain yield attributes. In previous studies, Fe content of roots was found to decrease with the increasing level of $\mathrm{S}$ applications from 30 to $120 \mathrm{mg} \mathrm{S} \mathrm{kg}^{-1}$ (Wu et $a l ., 2014)$ and that at excessive $\mathrm{S}$ supply $\mathrm{Fe}$ accumulation in the shoot declines $\mathrm{Hu}$ et al., (2007) on the other hand demonstrated a positive relation between $\mathrm{Fe}$ and $\mathrm{S}$ nutrition in rice seedlings.

Significant reduction in shoot growth under combined deficiency of $\mathrm{Fe}$ and $\mathrm{S}$ than the nutrient sufficient treatment supports their well-known essential role in plant metabolism and growth. Root mass was invariably higher under $-\mathrm{Fe}$ than $+\mathrm{Fe}$ conditions. Decrease in the number of functional proteins has also been reported under $\mathrm{S}$ and $\mathrm{Fe}$ deficiency (Muneer et al., 2013) which may be attributed to the depletion of biochemical attributes controlling signal transduction and gene function, due to excessive production of deleterious ROS (Luo et al., 2002; Choudhary et al., 2009). A better shoot mass with $+\mathrm{S}-\mathrm{Fe}$ deficiency over -S-Fe condition could be related to a better ability of plants to cope up $\mathrm{Fe}$ deficiency in the presence of $\mathrm{S}$ (Astolfi et al., 2010).

Optimum availability of $\mathrm{S}$ in plants would ensure an enhanced assimilation of $S$ and a relatively higher synthesis and availability of methionine for the production PS and nicotianamine. Changes in PS synthesis and release dynamics and the relative transcript expression of $\mathrm{S}$ and Fe-PS complex transporters (SULTR1; 1 and YSI) measured under $S$ and $F e$ deficient and sufficient condition, on one hand confirm the reports in 
literature that PS release is induced chiefly under $\mathrm{Fe}$ deficiency (Kobayashi and Nishizawa, 2012) but also indicate beyond doubt, towards an absolute requirement of $\mathrm{S}$ for the PS biosynthesis. Astolfi et al., (2012) reported that $\mathrm{Fe}$ deficient plants grown in presence of heavy metal cadmium partitioned more $\mathrm{S}$ for the biosynthesis of PS than for phytochelatin synthesis. Release of PS, in fact, has been causally related to the plants ability to tolerate Fe deficiency (Kobayashi et al., 2005; Forieri et al., 2013). The variation in PS release between $\mathrm{S}$ and Fe treatments and when compared with those reported in literature could be determined by cultivar sensitivity difference towards $\mathrm{Fe}$ deficiency and stringency of $\mathrm{Fe}$ deficiency condition achieved under the experimental setup. A lower release of PS by roots under $-\mathrm{S}-\mathrm{Fe}$ in the present study might be related to limitation in PS synthesis or in its actual release. To this effect, we measured the PS level of root tips that are actually available for the release. Results clearly showed that low PS release under S deprivation is not limited by release but by the availability of PS in the roots for their release.

Diurnal release pattern of PS was determined Fe deficiency (Zang et al., 1991) and under $\mathrm{Fe}$ and $\mathrm{Zn}$ deficiency (Singh et al., 2006) and was found to be identical. Plant $S$ nutrition is likely to affect PS biosynthesis via methionine substrate availability (Ma et al., 1995) and also methionine mediated effect on the diurnal rhythm of PS release under regulated $\mathrm{Fe}$ and $\mathrm{S}$ availability condition was found to be similar for both bread and durum wheat. PS synthesis and release mechanism was light regulated, as was also reported by Zhang and coworkers (1991).

The present study also elucidated the variation in induction of sulphate and $\mathrm{Fe}$ transporter SULTR1; 1 and YS1 under S and $\mathrm{Fe}$ sufficient and deficient condition. Data on relative abundance of SULTR1; 1 and YS1 gene transcripts clearly suggests a dynamic relationship and regulation of $\mathrm{S}$ and $\mathrm{Fe}$ on the activity of these transporters. Durum was more responsive to $S$ in terms of induction of high affinity transporter SULTR1; 1. Further this sulphate transporter was induced under low $\mathrm{S}$ availability condition only in the presence of Fe while YS1 was induced under Fe deficiency only when $\mathrm{S}$ was present. The regulatory mechanism of SULTR1; 1 gene expression was studied using inhibitors of transcription, translation and protein phosphorylation/dephoshphorylation by Nakashita et al., (2004). SULTR1; 1 expression in cortex and epidermis of roots was highly regulated by $S$ deficiency in Arabidopsis (Takahashi et al., 2000; Yoshimoto et al., 2002). Buchner et al., (2010) and Ciaffi et al., (2013) investigated the effect of $\mathrm{Fe}$ and $\mathrm{S}$ deprivation on expression profile of certain important transporters and enzymes involved in $\mathrm{S}$ assimilation and reduction and concluded that Fe-S interaction is a complex interplay of transcriptional/translational and post translational mechanisms that are induced under $\mathrm{S} / \mathrm{Fe}$ deficiency. Importance of mugineic acid family of PS as Fe (III) chelator to improve $\mathrm{Fe}$ uptake from calcareous/alkaline soils is known (Kobayashi et al., 2012). Further, Curie et al., (2009) investigated and suggested the importance of nicotianamine (NA) and yellow strip-1 like (YSL1) transporters for higher metal uptake in plants. ZmYS1 was shown to function as proton coupled symporter for the uptake of PS and NA-chelated metals (Schaaf et al., 2004) and in barley (Murata et al., 2006).

In conclusion, results clearly indicate a complex interplay of physiological, transcriptional and translational factors operative at the plant root level that not only governs the interaction between $\mathrm{Fe}$ and $\mathrm{S}$ metabolism but also determine the effect of $\mathrm{S}$ 
nutrition on $\mathrm{Fe}$ deficiency tolerance. Requirement of sufficient Fe for the induction of high affinity S uptake transporter SULTR1; 1 is worth exploring further to gain insight into regulation of $\mathrm{S}$ uptake by Fe.

\section{Acknowledgement}

Financial support to first author from ICARIndian Agricultural Research Institute, New Delhi is thankfully acknowledged.

\section{Author Contribution}

VS executed the experiments, collected and analyzed the results, RRK and RP helped with qRTPCR experiment and analysis and BS conceptualized and facilitated the experiments and wrote the paper.

\section{Abbreviations}

S: Sulphur, Fe: Iron, PS: Phytosiderophore, SULTR1; 1: Sulphur Transporter 1; 1, YS1: Yellow Stripe 1

\section{References}

Aciksoz SB, Yazici A, Ozturk L, Cakmak I., 2011. Biofortification of wheat with iron through soil and foliar application of nitrogen and iron fertilizers. Plant soil 349: 215-225. doi: 10.1007/s11104011-0863-2

Astolfi S, Zuchi S, Hubberten HM, Panton R, Hoefgen R., 2010. Supply of sulphur to S-deficient young barley seedlings restores their capability to cope with iron shortage. J Exp Bot 61: 799-806. doi: 10.1093/jxb/erp346

Astolfi S, Zuchi S, Neumann G, Cesco S, Di Toppi LS, Pinton R., 2012. Response of barley plants to $\mathrm{Fe}$ deficiency and $\mathrm{Cd}$ contamination as affected by $\mathrm{S}$ starvation. J Exp Bot 63: 1241-1250. doi: $10.1093 / \mathrm{jxb} / \mathrm{err} 344$
Briat JF, Lobreaux S., 1997. Iron transport and storage in plants. Trends Plant Sci 2: 187-193. doi: 10.1016/S13601385(97)01033-9

Buchner P, Parmar S, Kriegel A, Carpentier M, Hawkesford MJ., 2010. The sulfate transporter family in wheat: Tissuespecific gene expression in relation to nutrition. Mol Plant 3: 374-389. doi: 10.1093/mp/ssp119

Cakmak I, Erenoglu B, Gut KY, Derici R, Rolmheld V., 1998. Light-mediated release of phytosiderophores in wheat and barley under iron or zinc deficiency. Plant Soil 202: 309-315. doi: 10.1023/A:1004384712817

Cakmak I., 2008. Enrichment of cereal grains with zinc: agronomic or genetic biofortification? Plant Soil 302: 1-17. doi: 10.1007/s11104-007-9466-3

Choudhary MK, Basu D, Datta A, Chakraborty N, Chakroborty S., 2009. Dehydration-responsive nuclear proteome of rice (Oryza sativa L.) illustrates protein network, novel regulators of cellular adaptation, and evolutionary. Mol Cell Prot 8: 15791598. doi: 10.1074/mcp.M800601MCP200

Ciaffi M, Paolacci AR, Celletti S, Catarcione G, Kopriva S, Astolfi S., 2013. Transcriptional and physiological changes in the $\mathrm{S}$ assimilation pathway due to single or combined $\mathrm{S}$ and $\mathrm{Fe}$ deprivation in durum wheat (Triticum durum L.) seedlings. J Exp Bot 64: 1663-1675. doi: 10.1093/jxb/ert027

Curie C, Cassin G, Couch D, Divol F, Higuchi K, Le Jean M, Misson J, Schikora A, Czernic P, Mari S., 2009. Metal movement within the plant: Contribution of nicotianamine and yellow stripe 1-like transporters. Ann Bot 103: 1-11. doi: 10.1093/aob/mcn207

Curie C, Panavience Z, Loulergue C, 
Dellaporta SL, Briat JF, Walker EL., 2001. Maize yellow stripe1 encodes a membrane protein directly involved in Fe(III) uptake. Nature 409: 346- 349. doi: $10.1038 / 35053080$

Droux M., 2004. Sulfur assimilation and role of sulfur in plant metabolism: a survey. Photosynth Res 79: 331-348. doi: 10.1023/B:PRES.0000017196.95499.11

Forieri I, Wirtz M, Hell R., 2013. Toward new perspectives on the interaction of iron and sulfur metabolism in plants. Front Plant Sci 4:357. doi:10.3389/fpls.2013.00357

Gilbert S, Clarkson DT, Cambridge M, Lambers H, Hawkesford MJ., 1997. Sulphate-deprivation has an early effect on the content of ribulose 1,5bisphosphate carboxylase/oxygenase and photosynthesis in young leaves of wheat. Plant Physiol 115: 1231-1239. doi: 10.1104/pp.115.3.1231

Gries D, Runge M., 1995. Responses of calcicole and calcifuge poaceae species to iron-limiting conditions. Bot Acta 108: 482-489. doi: 10.1111/j.14388677.1995.tb00525.x

Hawkesford MJ., 2000. Plant responses to sulphur deficiency and the genetic manipulation of sulphate transporters to improve S- utilization efficiency. J Exp Bot 51:131-138.

Hell R, Stephan UW., 2003. Iron uptake, trafficking and homeostasis in plants. Planta 216: 541-551. doi: 10.1007/s00425-002-0920-4

Hu ZY, Zhu YG, Li M, Zhang LG, Cao ZH, Smith FA., 2007. Sulfur (S)-induced enhancement of iron plaque formation in the rhizosphere reduces arsenic accumulation in rice (Oryza sativa L.) seedlings. Environ Pollut 147: 387-393. doi: 10.1016/j.envpol.2006.06.014

Järvan M, Edesi L, Adamson A, Lukme L, Akk A., 2008. The effect of sulphur fertilization on yield, quality of protein and baking properties of winter wheat. Agron Res 6: 459-469.

Khobra R, Ahuja S, Singh B., 2014. Chlorophyll biosynthesis as the basis of iron use efficiency under iron deficiency and its relationship with the phytosiderophore synthesis and release in wheat. Indian J Plant Physi 19: 330337. doi: 10.1007/s40502-014-0112-9

Kobayashi T, Nishizawa NK., 2012. Iron uptake, translocation, and regulation in higher plants. Annu. Rev Plant Biol 63: 131-152. doi: 10.1146/annurev-arplant042811-105522

Kobayashi T, Suzuki M, Inoue H, Itai RN, Takahashi M, Nakanishi H, Nishizawa NK., 2005. Expression of ironacquisition-related genes in irondeficient rice is co-ordinately induced by partially conserved iron-deficiencyresponsive elements. J Exp Bot 56: 1305-1316. doi: 10.1093/jxb/eri131

Kuwajima K, Kawai S., 1997. Relationship between sulfur metabolism and biosynthesis of phytosiderophores in barley roots. In:Ando T, Fujita K, Mae T, Matsumoto H, Mori S, Sekiya J, eds. Plant Nutr-for Sustainable Food Production and Environment. Dordrech, The Netherlands: Kluwer Academic Publishers, 285-286.

Lindsay WL, Schwab AP., 1982. The chemistry of iron in soils and its availability to plants. J Plant Nutr 5: 821-840.

doi: 10.1080/01904168209363012

Luo S, Ishida H, Makino A, Mae T., 2002. $\mathrm{Fe}+2$-catalyzed site specific cleavage of the large subunit of ribulose 1,5bisphosphate carboxylase close to the active site. J Biol Chem 277: 1238212387. doi: 10.1074/jbc.M111072200

Ma JF, Shinada T, Matsuda C, Nomoto K., 1995. Biosynthesis of phytosiderophores, mugineic acids, associated with methionine cycling. J 
Biol Chem 270: 16549-16554. doi: 10.1074/jbc.270.28.16549

Maruyama-Nakashita A, Nakamura Y, Watanabe-Takahashi A, Yamaya T, Takahashi H., 2004. Induction of SULTR1; 1 sulfate transporter in Arabidopsis roots involves protein phosphorylation/ dephosphorylation circuit for transcriptional regulation. Plant Cell Physiol 45: 340-345. doi: 10.1093/pcp/pch029

Muneer S, Lee BR, Bae DW, Kim TH., 2013. Changes in expression of proteins involved in alleviation of Fe-deficiency by sulfur nutrition in Brassica napus L. Acta Physiol Plant 35: 3037-3045. doi: 10.1007/s11738-013-1336-4

Murata Y, Ma JF, Yamaji N, Ueno D, Nomoto K, Iwashita T., 2006. A specific transporter for iron(III)phytosiderophore in barley roots. Plant J 46: 563-572. doi: 10.1111/j.1365313X.2006.02714.X

Ostaszewska-Bugajska M, Juszczuk IM., 2016. Changes in the OXPHOS system in leaf and root mitochondria of Arabidopsis thaliana subjected to longterm sulphur deficiency. Acta Physiol Plant 38: 1-16. doi:10.1007/s11738016-2155-1.

Pfaffl MW., 2001. A new mathematical model for relative quantification in realtime RT-PCR. Nucleic Acids Res 29:e45. doi:10.1093/nar/29.9.e45

Pompa M, Giuliani MM, Giuzio L, Gagliardi A, Di Fonzo N, Flagella Z., 2009. Effect of sulphur fertilization on grain quality and protein composition of durum wheat (Triticum durum Desf.). Ital J Agron 4:159-70. doi: 10.4081/ija.2009.4.159

Reichman SM, Parker DR., 2007 Critical evaluation of three indirect assays for quantifying phytosiderophores released by the roots of Poaceae. Euro J Soil Sci 58: 844-853. doi:10.1111/j.1365- 2389.2006.00874.x

Römheld V, Marschner H., 1990. Genotypical differences among graminaceous species in release of phytosiderophores and uptake of iron phytosiderophores. Plant Soil 123: 147-53.

Salvagiotti F, Castellarín JM, Miralles DJ, Pedrol HM., 2009. Sulfur fertilization improves nitrogen use efficiency in wheat by increasing nitrogen uptake. Field Crops Res 113: 170-177. doi: 10.1016/j.fcr.2009.05.003

Schaaf G, Ludewig U, Erenoglu BE, Mori S, Kitahara T, Von Wirén N., 2004. ZmYS1 functions as a proton-coupled symporter for phytosiderophore and nicotianamine-chelated metals. J Biol Chem 279: 9091-9096. doi: 10.1074/jbc.M311799200

Singh B, Kumar S, Singh BK., 2006. Phytosiderophore production and its release is related to Zn-efficiency of wheat under Zn-deficiency, In. Wheat for tropical areas, Eds Nayeem KA, IARI Publication 247-252.

Tabatabai MA, Bremner JM., 1970. A simple turbidimetric method of determining total sulfur in plant material. Agron $\mathrm{J}$ 62: 805-806.

Takagi S., 1976. Naturally occurring ironchelating compounds in oat and riceroot washings. Soil Sci Plant Nutr 22: 423-433.

doi: 10.1080/00380768.1976.10433004

Takagi Si, Nomoto K, Takemoto T., 1984. Physiological aspect of mugineic acid, a possible phytosiderophore of graminaceous plants. J Plant Nutr 7: 469-477. doi: 10.1080/0190416840936 3213

Takahashi H, Kopriva S, Gior-dano M, Saito K, Hell R., 2011. Sulfur assimilation in photosynthetic organisms: molecular functions and regulations of transporters and assimilatory enzymes. Annu Rev Plant Biol 62: 157-184. doi: 
10.1146/annurev-arplant-042110103921

Takahashi H, Watanabe-Takahashi A, Smith FW, Blake-Kalff M, Hawkesford MJ, Saito K., 2000. The roles of three functional sulphate transporters involved in uptake and translocation of sulphate in Arabidopsis thaliana. Plant $\mathrm{J}$ 23: 171-182. doi: 10.1046/j.1365313x.2000.00768.x

White PJ, Broadley MR., 2009. Biofortification of crops with seven mineral elements often lacking in human diets-iron, zinc, copper, calcium, magnesium, selenium and iodine. New Phytol 182: 49-84. doi: 10.1111/j.1469-8137.2008.02738.X

Wu CY, Lu J, Hu ZY., 2014. Influence of sulfur supply on the iron accumulation in rice plants. Commun Soil Sci Plant Anal 45(8):1149-61. doi: 10.1080/00103624.2013.875189

Yoshimoto N, Takahashi H, Smith FW,
Yamaya T, Saito K., 2002. Two distinct high-affinity sulfate transporters with different in- ducibilities mediate uptake of sulfate in Arabidopsis root. Plant J 29: 465-473. doi: 10.1046/j.09607412.2001.01231.x

Zhang FS, Römheld V, Marschner H., 1991. Role of the root apoplasm for iron acquisition by wheat plants. Plant Physiol 97: 1302-1305. doi: 10.1104 /pp. 97.4.1302

Zhao FJ, Hawkesford MJ, McGrath SP., 1999. Sulphur assimilation and effects on yield and quality of wheat. J Cereal Sci 30: 1-17. doi:10.1006/jcrs.1998. 0241

Zuchi S, Cesco S, Astolfi S., 2012. High S supply improves $\mathrm{Fe}$ accumulation in durum wheat plants grown under $\mathrm{Fe}$ limitation. Environ Exp Bot 77: 25-32. doi:10.1016/j.envexpbot.2011.11.001

\section{How to cite this article:}

Vasundhara Sharma, Ranjeet Ranjan Kumar, Raghunath Pandey and Bhupinder Singh. 2018. Regulation of phytosiderophore (PS) and Yellow Stripe-1 (YS1) transporter activity by sulphur (S) and that of high-affinity sulphate (SULTR1; 1) transporter by iron $(\mathrm{Fe})$ in wheat. Int.J.Curr.Microbiol.App.Sci. 7(01): 71-88. doi: https://doi.org/10.20546/ijcmas.2018.701.010 